\title{
Comida e visualidade
}

ELAINE DE AZEVEDO

SHAY PELED

\section{Resumo}

Este estudo teórico-conceitual coloca em evidência temas e debates ligados à alimentação sob uma perspectiva sociopolítica e cultural, a partir de diferentes mídias audiovisuais - cinema, TV, reality shows e vídeos veiculados na internet. $\mathrm{O}$ artigo se debruça particularmente sobre filmes

Palavras-chave: Alimentação, cinema, visualidade no cinema que mobilizam a alimentação como eixo transversal das tramas. A ideia é complexificar a comida como temática audiovisual e pensá-la como estratégia sensorial. 


\section{Food and visuality}

\section{Abstract}

This theoretical-conceptual study highlights issues and debates related to food under a socio-political and cultural perspective, from different audiovisual media - cinema, TV, reality shows and Internet videos. The article focuses particularly on movies that mobilize the food as a transversal axis of the plots. The idea is to complexify food as a visual theme and as a sensorial strategy. 


\section{Comida y visualidad}

\section{ELAINE DE AZEVEDO}

SHAY PELED

\section{Resumen}

Este estudio teórico-conceptual pone de relieve temas y debates relacionados a la alimentación, desde la perspectiva socio-política y cultural, partiendo de diferentes medios audiovisuales - cine, TV, reality shows y videos transmitidos en internet. El artículo se centra, particularmente, en películas de cine que toman como tema central de sus tramas la alimentación. La idea es problematizar la comida como Alimentación, cine, visualidad tema audiovisual y pensarla como estrategia sensorial. 


\section{Alimentação e seus Signos}

Não há dúvidas. A comida comove e mobiliza sentidos, prazeres e ideias. Na abordagem estruturalista de Roland Barthes (2008), a alimentação constitui signos em um sistema de informação capaz de gerar diferentes mensagens.

O indivíduo nutre-se de imaginários e significados, compartilhando representações coletivas e uma intimidade peculiar ao incorporar a comida na interioridade corporal humana. O potencial simbólico da comida é central para a construção do senso de identidade individual e coletiva (FISCHLER, 2001; 1988).

Para além do seu potencial simbólico, estrutural ou estruturante, a alimentação também pode ser compreendida como continuidade ou rompimento com a tradição; como distinção de gêneros e etnias; como estratégia de prazer e lubrificação de interações sociais ou como fomentadora de intolerâncias, divisões sociais, solidão, incertezas e controvérsias. Mais recentemente, práticas de ativismo alimentar questionam o antropocentrismo e o sistema agroalimentar dominante, apoiando novas formas de se alimentar e propostas de manejo agropecuário sustentável, transformando o comer em um ato político e ambiental.

Esse potencial cultural expande-se sob diversas formas de visualidade que alimentam todos os sentidos dos consumidores audiovisuais e virtuais. Algumas dessas formas serão aqui exploradas conceitualmente a partir de autores das áreas das Ciências Humanas e Sociais e da Comunicação para enfatizar a relação central do estudo - comida e visualidade.

\section{Gastromídia}

Os programas culinários na TV tornam-se cada vez mais atraentes. Talvez devido ao gradual afastamento do meio rural 
onde a comida é produzida ou à crescente especialização da profissão de cozinheiro, uma vez que cada vez menos as pessoas comem ou aprendem a cozinhar em casa. Provavelmente esses programas não fariam tanto sucesso anos atrás, quando menos pessoas viviam nos centros urbanos e cozinhar era uma prática cotidiana e trivial, inerente ao papel da boa esposa e mãe. Essa gastromídia, para usar o conceito de Jacob (2000), garante a visualidade da culinária e estabelece vínculos diretos entre indivíduos, comida e cozinha.

A comida promove uma sensação de conforto (que remete ao conceito de comfort food) e pertencimento - sensações cada vez mais pulverizadas na urbanização contemporânea. Os programas culinários investem em experiências gastronômicas que remetem à infância ou a experiências coletivas, prazerosas e afetivas. Esses programas apostam na ideia de revelação do novo como se os segredos dos chefs e dos pratos disponíveis em restaurantes caros ou em cozinhas distantes fossem caridosamente revelados aos espectadores.

Jacob (2012, p. 124) resume essa experiência de comunicação ao enfatizar que o "gastrônomo alimenta-se do novo e do exótico em igual proporção [...] a ânsia pelo novo expõe e coloca como valor de troca comunicativo a imagem do chef e de sua cozinha”. Na mesma direção, Heldke (2001) percebe a gastronomia como forma de endossar a recorrente fascinação branca pela comida étnica. A busca por novas e remotas culturas e experiências foi o motor dos primeiros antropólogos, exploradores e colonizadores.

A alta gastronomia na televisão também contribui para democratizar o que Nascimento (2007, p. 220) chama de "hobby de gente refinada" ao colocar indivíduos comuns mais perto dos foodies. Esse termo foi criado em 1984 pelos escritores ingleses Paul Levy e Ann Barr para designar pessoas de alto nível intelectual que têm um agudo interesse por experiências gastronômicas gourmets e extravagantes.

O chef catalão Santi Santamaria, entrevistado pelo sociólogo Carlos Alberto Doria (2013), aborda o aspecto político e ambiental da gastronomia. Voltar a comer em casa, utilizando alimentos orgânicos provenientes de agricultores familiares locais, torna-se uma forma de resistência à globalização e à hegemonia do sistema agroalimentar dominante, delineando assim a função social do cozinheiro.

Para alcançar essas sensações - e esclarecer as crescentes controvérsias que rondam a comida - nunca se veiculou tanta informação sobre alimentação em programas televisivos que 
ensinam técnicas ancestrais e revelam segredos culinários. São reality shows que mostram a feitura de doces monumentais para festas e disputas de quem prepara o melhor prato. Na emissora brasileira mais popular são transmitidos os programas: "Mais Você" com seu momento receitas; "Estrelas" com vídeos de receitas feitas por celebridades no papel de chefs e "Bem Estar" que fala de alimentação e saúde. Já o canal GNT veicula diversos programas de culinária: "Tempero de Família", "A Cozinha Caseira de Annabel”, "Cozinha Mediterrânea”, "Cozinha Prática”, "Que Marravilha!", "Viagem Gastronômica”, "Diário de Olivier”, "Nigella", "Receitas do Chuck" e "GNT Receitas". Nos canais pagos também são muitas opções: "Fome de quê?", "The Taste Brasil, Food Truck- a batalha", "Kitchen Nightmares", "Top Chef”, "Just Desserts", "Man vs Food", "Ace of Cakes", entre outros.

Na televisão, os reality shows lideram a audiência dos telespectadores em busca da intimidade dos personagens. "Cake Boss", uma série de televisão estadunidense, se debruça sobre o negócio de Buddy Valastro e sua família que confeccionam bolos estruturais. No seriado gastronômico "Chef's Table" cada episódio revela a rotina de grandes chefs ao redor do mundo; como cozinham, como vivem e o que comem. Apesar do foco na gastronomia, tais formatos de reality shows apostam na receita infalível de mostrar comida e intimidade.

Ao se deparar com a discussão da alimentação em todas as mídias possíveis, o espectador está sujeito à influência de diversos discursos que servem aos interesses do mercado em detrimento da saúde, mudando até mesmo concepção do que é saudável como pode se ver na resposta de um auxiliar de enfermagem questionado sobre tal conceito: "saudável era a alimentação observada na novela de televisão...” (SALLES, 2004 apud PROENÇA, 2010, p. 46).

Sob a influência da globalização e com o destaque que a gastronomia garante nas mídias contemporâneas, restaurantes, pratos e alimentos de diferentes culturas são facilmente encontrados nas ruas de qualquer cidade brasileira. No projeto transmídia (série e websérie) "Latitudes", de Felipe Braga, cada episódio acontece em uma cidade de um país diferente. $\mathrm{O}$ episódio em Veneza inicia com o protagonista saindo de um restaurante oriental, causando estranheza no telespectador que espera assistir à degustação de uma suculenta massa italiana.

É interessante também notar a representação das diferentes culturas através dos filmes e programas. Além de apresentar como é a forma de comer em outras sociedades, essas mídias tendem a fortalecer arquétipos de como um determinado 
povo se comporta frente à alimentação. Assim, é permitido ao japonês sorver a sopa fazendo ruídos para demonstrar que saboreia o prato ou ao árabe comer com as mãos. Do francês esperam-se refeições refinadas e minimalistas, com apelo estético e do chinês aceita-se que qualquer ser vivo que se mexe possa ser incorporado ao prato.

Todas as mídias têm o seu poder de influência. Entretanto, a televisão como mídia inclusiva, de fácil assimilação e disseminação, contribui para diversificar as controvérsias e os riscos alimentares, bem como para criar dietas ideais, desprovidas de valores culturais e funções sociais discutidos por Azevedo (2009; 2004).

A influência da propaganda sobre os transtornos alimentares como obesidade, anorexia, bulimia, tem sido extensamente estudada e veiculada por órgãos preocupados com a saúde públi$\mathrm{ca}^{1}$. Estela Renner evidencia essa temática no universo infantil ao tratar a relação entre a criança, a obesidade e a propaganda infantil abusiva em seu documentário "Muito além do peso", de 2012.

A dimensão audiovisual das diferentes mídias - TV, cinema e internet - contribui para disseminar o referencial de beleza ideal, impulsionado pela ideia de saudabilidade do corpo magro, sob influência do fenômeno de "lightização da existência" identificado por Santos (2008, p.18). Esse construto social, passaporte para o mundo do sucesso, é objeto do curta-metragem de animação "Super Venus"2 (2013), do cineasta francês Frédéric Doazan, para mostrar a transformação do corpo feminino em busca da perfeição.

As mídias sociais não escapam da era do modismo alimentar e milhões de comedores postam suas habilidades culinárias, seus anseios ativistas e suas composições gastroalimentares. A (antiga) intimidade e o cotidiano alimentar são disseminados através de celulares, tablets e computadores. No Instagram, por exemplo, o uso no hashtag \#foodporn é amplamente usado para exibir as experiências gastronômicas ou culinárias dos usuários.

Eve Turow (2015) se volta para a geração Yum formada por jovens estadunidenses obsessivos por comida e por receitas e experiências gastronômicas, sentimento causado pela privação sensorial que a era digital promove. A comida e a o comer fomentariam a emoção e os múltiplos sentidos que faltam aos solitários 'gastronautas' à frente das telas.

Come-se só, mas se compartilha a visualidade alimentar com milhões de usuários. É a ideia da visualidade extrema alimentando a invisibilidade (JACOB, 2012). 


\section{A comida nas grandes telas: mais do que pipoca}

"Cinema e comida. Dois grandes prazeres humanos cada vez mais juntos". A chamada da jornalista Giuliana Toledo (2013) divulga inúmeros festivais e projetos que misturaram cinema e comida em São Paulo. Um shopping lança um projeto de sessões de cinema com menus que dialogam com o filme, criados por grandes chefs de cozinha. Um cinema faz sessões e combina obras brasileiras com pratos dentro da Semana Mesa SP. Uma mostra ("Doc Gastronômica") apresenta vinte documentários de diferentes países sobre alimentação. $\mathrm{O}$ gênero food film e o festivais "Food and Films" ${ }^{\text {"3 }}$ se espalham por diferentes cidades e países.

O site "Gastronomismo" ou "comida de cinema", projeto de Isadora Becker, ensina a fazer receitas inspiradas nos pratos que aparecem nos filmes: ovos na cestinha de "V de Vingança"; ponche rosa de "Across de Universe"; hambúrguer Big Kahunar de "Pulp Fiction"; cookies de "Alice no país das maravilhas"; canapés de "Uma linda mulher"; courtesan au chocolate do "Grande Hotel Budapest"; folhado dinamarquês da "Bonequinha de luxo"; crème brûlée de "Amélie Poulain"; manjar turco das "Crônicas de Nárnia"; croissant au chcolat de "Simplesmente complicado"; apfelstrudel de "Bastardos inglórios"; cerveja amanteigada de "Harry Potter"; pizza de marguerita de "Comer rezar e amar"; sanduíche de salada de ovos de "O que há tigresa?"; gaspacho (sem soníferos) de "Mulheres a beira de ataque de nervos" e coxinhas de frango de "Estômago". As pessoas parecem ávidas por vivenciar a sedução da mesa e por ver comida do e no cinema, ampliando assim seus conceitos "gastronômicocinematográficos", como sugere Siani (2014).

As imagens manipulando o desejo de comer e as representações simbólicas da comida aparecem no cinema sob a mesma construção que a literatura utilizou para expressar a influência da linguagem sobre as sensações. Personagens que lidam com a culinária ou fazem referências a comidas são explorados desde Shakespeare que se refere aos "lábios cerejas" de Helena em "Sonhos de uma noite de verão". Entretanto, remete-se a inglesa Joanne Harris, autora da trilogia gastronômica "Vinho de Amoras", "Cinco Quartos de Laranja" e "Chocolate", a invenção do neologismo "gastrorromance", gênero de literatura que consiste em conferir qualidades alimentares aos personagens principais, trazendo a culinária como temática central da trama. Outras publicações inspiradas na gastronomia fizeram sucesso: 
“Como água para chocolate", de Laura Esquivel (1994), "A festa de Babette e outras histórias do destino", de Isak Dinesen (1999) que, assim como o romance de Harris, "Chocolate", originaram filmes com os mesmos nomes nos anos de 1992, 1987 e 2000, respectivamente (NASCIMENTO, 2007).

Na maioria das produções cinematográficas, a alimentação, uma das principais atividades humanas, é usada de forma ilustrativa, como por exemplo, um jantar em família ou um café entre amigos através dos quais a trama central se desenvolve. Porém, alguns diretores elegem a alimentação como protagonismo simbólico. Cardoso e Antonio (2006), ao analisarem o clássico "Como água para chocolates" (1992) e o filme "Açaí com Jabá" (2001), mostram que nesses filmes as práticas alimentares assumem papel central no roteiro, mediando relações sociais e impulsionando as ações da trama.

Um filme em que a temática da comida aparece como representação do extremo prazer e do ilimitado irrestrito é a "A Fantástica fábrica de Chocolates", de Tim Burton (2005), no qual Willy Wonka, o excêntrico dono de uma famosa fábrica de chocolate desativada, decide premiar cinco crianças oferecendo uma visita ao local de desejo. Em artigo que analisa esse filme, Vander Casaqui e Antonio Roberto Chiachiri destacam:

[...] a construção imagética do filme parece nos indicar o caminho do domínio da representação rumo a um imaginário fantástico, porém, é evidente que toda construção representativa não se restringe apenas à imagem, mas é esta que aí se apresenta mais forte. Como fazer brotar, por meio de imagens, na mente de um intérprete, um delicioso mundo de chocolate sem tocar no seu imaginário, no seu desejo, no salivar de sua boca? Esse fazer brotar é o domínio da representação. Charles Sanders Peirce, o pai da semiótica geral moderna, define representar como: "estar para, quer dizer, algo está numa relação tal com o outro que, para certos propósitos, ele é tratado por uma mente como se fosse aquele outro" (CASAQUI; CHIACHIRI, 2007, s/p, grifo do autor).

Os mesmos autores ainda ressaltam que quando o filme acaba, "[...] o sabor permanece na mente daqueles que desfrutaram os instantes de prazer gustativo que emanaram da tela" $(2007, \mathrm{~s} / \mathrm{p})$. Nesse caso, o alimento aparece como potencializador de simbolismo que tenta representar ou estar no lugar de. Imagens aparecem como signos indiciais que apontam 
um mundo de chocolate que se pode definir como concreto ou aquele que desperta as fantasias do viver.

Alguns filmes atribuem capacidades gastronômicas aos protagonistas como forma de complexificar relações, como no "Estômago", de Marcos Jorge (2007). No filme, um nordestino chamado Nonato, chega a São Paulo e encontra um trabalho como cozinheiro num bar popular, descobrindo um carinho pela culinária e um dom, antes desconhecido: o de preparar coxinhas que se tornam um sucesso comercial do estabelecimento e lhe garante popularidade e sobrevivência. O protagonista divide-se, essencialmente, entre duas necessidades biológicas, comer e fazer sexo, ambas permeadas pelo prazer e pela estrutura do poder que tem dois eixos - a gastronomia e o sexo - determinantes para mostrar quem come quem na trama. A gastronomia ainda garante o reconhecimento social do protagonista no bar que ao ser preso deixa de ser um simples presidiário para se tornar um prestigioso cozinheiro da cadeia (PINTO, s/d).

"Julie \& Julia" (2009), de Nora Ephron, é baseado em histórias reais, intercalando duas tramas em tempos diferentes, nas quais, ambas protagonistas, são cozinheiras e não se conhecem pessoalmente. O prazer pela culinária amarra a tradição e a modernidade e constrói um laço afetivo entre as duas mulheres separadas pelo tempo real, tal como previsto por Durkheim (1996), ao considerar o potencial da comida na construção de um vínculo artificial de parentesco ou afetividade.

O resultado final do jantar de "A festa de Babette", dirigido por Gabriel Axel, expressa plenamente esse sentimento de comunhão proporcionado pela comensalidade. Na gélida Dinamarca, após uma sedutora refeição preparada por Babette, os severos e distanciados irmãos da congregação local vivenciam uma genuína experiência de fraternidade e reconciliam-se entre si (SANTOS, 2010). A comida costurando afetos e encontros, nesse caso familiares, aparece nos filmes "Alimento da Alma" (1997), de Fatih Akin e "Comer, Beber, Viver" (1995), de Ang Lee.

O filme de 2010 do diretor Jorge Coira, "18 comidas", foca na prática da comensalidade urbana como estratégia transversal as tramas dos diferentes (des)encontros. O enredo se passa na cidade de Santiago, Chile, no entrelaçamento de 24 personagens, seis histórias, 18 refeições ou "atos de refazer forças", como define o dicionário. O músico de rua, Edu, vai almoçar com seu antigo amor, uma dona de casa depressiva e solitária; um par romântico toma café da manhã depois de acordarem juntos após sua primeira noite; um homem de negócios vai 
jantar na casa de seu irmão Victor, homossexual não assumido, que apresenta na ocasião seu novo namorado, e Vladimir, um ator e celebridade local, prepara três refeições para uma mulher misteriosa que nunca chega a tempo para degustar seus pratos e sua companhia.

Dentro dessa ideia de comida aproximando pessoas, um web projeto colaborativo do cineasta francês Jonas Pariente - Grandmas Project ${ }^{4}$ - chama cineastas e filmmakers para produzir um curta sobre suas avós, usando a transmissão de receitas culinárias para abordar as heranças afetivas passadas entre as diferentes gerações. As receitas revelam, na 'linguagem das avós', vivências sexistas e eventos históricos como o surgimento do movimento feminista, a decolonização, as grandes guerras e o nazismo.

Tramas gastronômicas, nas quais o protagonista é um cozinheiro e das telas exalam aromas culinários deixando o público esfomeado, têm lugar garantido no cinema. Entre muitos produzidos durante os anos 2000, destacam-se os filmes "Chef", de Jon Favreau, "Os sabores do palácio", dirigido por Christian Vincent, "O Tempero da Vida", de Tassos Boulmetis e "Simplesmente Martha”, de Sandra Nettelbeck. O estilo animação também ganhou seu cozinheiro antropoformizado na forma de um habilidoso rato, em Ratatouille (2007), dirigido por Brad Bird.

Uma receita de sucesso incorpora comumente os ingredientes comida e sexo. Ambos são fenômenos biológicos e culturais, prazerosos, nutritivos e permitem explorar uma variedade de prescrições. A sedução da comida permite usá-la como metáfora sexual para enfatizar o erotismo e, frequentemente, o poder masculino sobre as mulheres. A ideia de 'comer' remete às relações sexuais - sendo frequentemente o mais forte que come o mais fraco ou o macho que come a fêmea, como aponta Fischler em entrevista a Goldenberg (2012). Outras expressões alimentares enfatizam o erotismo alimentar como no caso do 'homem/mulher gostoso/a' ou das 'mulheres frutas', fenômeno do funk carioca e da mídia erótica.

Para Nascimento (2007, p. 111), o "vocabulário amoroso se entrelaça constantemente com o gastronômico [...] implícito nas nostálgicas expressões "pele de pêssego", "olhos amendoados" ou "cor de avelã", "boca de cereja", "lábios polpudos", "formas apetitosas", sem esquecer a "lua-de-mel" que, tantas vezes, acaba com o caldo entornado".

Em muitos filmes o alimento é aliado ao amor romântico e ao erotismo, trazendo cenas em que sexo e comida são deliciosamente compartilhados. Dois clássicos exemplos são 
a polêmica manteiga do "O Último Tango em Paris "(1972), de Bernardo Bertolucci, e os morangos de " 9 1/2 semanas de amor" (1986), dirigido por Adrian Lyne.

No filme israelense "And thou Shalt love" (2008), de Chaim Elbaum, um judeu ortodoxo adere a um longo jejum na tentativa de curar sua homossexualidade. Em "Pecado da Carne", o diretor Haim Tabakman usa a imagem de uma grande peça de carne pendurada na câmera frigorífica no momento do encontro impossível entre o açougueiro religioso e seu sedutor ajudante. Provavelmente, em um romance homossexual protagonizado por mulheres, tal simbolismo não seria utilizado, já que a carne carrega a conotação de comida e poder masculinos, simbolizados arquetipicamente pela força física, pela caça, pelo belicismo e pelo consumo de alimentos que estimulam a virilidade.

A relação entre sexualidade e alimento aparece também no romance "Gabriela, cravo e canela", de Jorge Amado (1958), adaptado três vezes para televisão na história da telenovela brasileira (em 1960, 1975 e 2012) e, ainda foi tema de um filme dirigido em 1983 por Bruno Barreto. A obra narra o caso de amor entre o árabe Nacib e a sertaneja Gabriela, contratada para ser cozinheira em seu bar Vesúvio. É lá que Gabriela mistura os temperos orientais com os segredos da Bahia e atrai fatalmente seu patrão. Gabriela, como ícone de sedução, de brejeirice, de vigorosidade sexual, de apelo à ingenuidade e malícia feminina foi utilizada por Ribeiro e Souza (2006) para problematizar relações de gênero, patriarcalismo, sexualidade e poder masculino.

Um dos melhores exemplos de como a comida pode expressar o amor romântico está no filme "Como água para chocolates”, de Alfonso Arau (1992). Em cena clássica, a apaixonada e melancólica Tita cozinha para seu grande amor, agora casado com sua irmã. Ao servir a comida, todos na mesa choram, saboreando o triste banquete e compartilhando, inadvertidamente, a poesia de Mia Couto (2009, p.45): “cozinhar é o mais privado e arriscado ato. No alimento se coloca ternura ou ódio. Na panela se verte tempero ou veneno. Cozinhar não é serviço. Cozinhar é um modo de amar os outros".

Outro filme que mistura sexo e comida, agora sob a perspectiva da gula, da violência, da escatologia e do canibalismo é o clássico "O Cozinheiro, o Ladrão, sua Esposa e o Amante”, de Peter Greenway (1989), que se passa no restaurante Le Hollandais. Nesse cenário gastronômico, um gângster e seus capangas se dedicam aos prazeres da mesa, enquanto sua esposa o trai com um solitário frequentador do restaurante, acobertada pelo chefe de cozinha francês. Para Ferraz (2012, 
s./p.), o affair percorre o caminho oposto das adoradas iguarias do marido uma vez que "começa no banheiro, floresce à mesa, explode na cozinha, se refugia pelo frigorífico e escapa pelo caminhão de entrega de carne".

E os simbolismos alimentares não se esgotam. Nascimento (2007, p. 9o) cita Lima (1999) para mostrar que quando se consome ou manipula determinado alimento como símbolo, ele transcende a qualidade de objeto, pois transmite um significado, como "[...] um fixador psicológico no plano emocional". No filme russo "O Encouraçado Potemkim" (1925), o diretor Eisenstein utilizou um pedaço de carne podre para simbolizar a decadência de um regime político. A dinâmica do café da manhã foi utilizada por Welles para mostrar a deterioração do primeiro casamento de Charles Foster Kane, em "Cidadão Kane" (1941), dirigido por Orson Welles. Em "The big swallow", rodado em 1901, Williamson, diretor dinamarquês encerra o filme com a câmera sendo engolida pela bocarra do protagonista. A busca obsessiva de provar carne de boi motivou e modificou a vida de um caipira brasileiro em "A marvarda carne" (1985), dirigido por André Klotzel. "A força do desejo é expressa no alimento nunca dantes experimentado, imaginado como a maior das delícias e cuja busca justifica sacrifícios e muita persistência" (NASCIMENTO, 2006, p.92).

\section{Ativismo alimentar nos documentários}

Em vários trabalhos audiovisuais, o alimento é inserido na perspectiva do ativismo alimentar, denunciando e criticando o sistema agroalimentar dominante e as novas práticas alimentares contemporâneas. No seriado "Super Size Me" (2004), um documentário estadunidense dirigido e protagonizado por Morgan Spurlock, o alimento é usado como denúncia do sistema fast food. Spurlock passa 30 dias comendo apenas no McDonald's e alcança resultados desastrosos para sua saúde. O documentário é impactante na medida em que é verdadeiro e envolve riscos reais. Outro documentário produzido no Brasil em duas versões, "O Veneno está na Mesa" (2011), de Silvio Tendler, revela o escândalo dos agrotóxicos por meio do depoimentos de agricultores, representantes de consumidores, representantes de multinacionais, da Agência Nacional de Vigilância Sanitária (ANVISA) e dos movimentos ligados a Agroecologia e segue o mesmo caminho que o docu- 
mentário "In Organic we trust" (2012), do diretor Kip Pastorm, que questiona a produção de alimentos nos EUA e os perigos do 'agriorganic business'.

Michael Pollan, um jornalista e ativista alimentar estadunidense, protagoniza quatro episódios no documentário "Cooked", de 2016, com o objetivo de conscientizar as pessoas sobre os bastidores da produção de alimentos, incentivando assim o retorno às praticas de cozinha tradicional.

Outro exemplo de ativismo alimentar em forma de documentário, agora a favor do vegetarianismo/veganismo e dos direitos dos animais é "A Carne é Fraca" (2005), produzido pelo Instituto Nina Rosa para abordar os impactos do carnivorismo na saúde humana, no bem-estar animal e no meio ambiente.

Trabalhando na lógica inversa, mostrando o positivo, os documentários "Brasil Orgânico" (2013), dirigido por Kátia Klock e Lícia Brancher e "Você sabe de onde vêm seus alimentos?" (2012), produzido pelo Coletivo Aura, enaltecem o modo de viver dos agricultores orgânicos em diferentes regiões do Brasil. São produções que cumprem funções sociopolíticas de revelar os bastidores da produção alimentar e apoiar sistemas agroalimentares sustentáveis. Outro exemplo de ativismo, agora a favor do direito humano à alimentação, é o clássico curta-metragem "Ilha das Flores", de 1989, dirigido por Jorge Furtado. O filme utiliza de uma história relacional entre personagens ficcionais e alimentos para falar criticamente das diferenças sociais dos catadores de lixo do local.

\section{Considerações finais: para além das lágrimas}

A veiculação das imagens e experiências gastronômicas pelas diferentes mídias sugere uma espetacularização de uma ação cotidiana descolada da sua intimidade - o ato de comer e preparar alimentos. As experiências gastronômicas na vida real são perseguidas pelo apelo de perfeição, prazer e enlevo que a cultura da imagem projeta.

Morin (200o) afirma que o plano da produção imagética transporta para um momento mágico, no qual a posse da representação equivaleria - por contiguidade - à posse do representado.

Tal magia, que também pode ser mais bem descrita como dimensão sensória do cinema, foi pensada por Maurice Merleau-Ponty, Vivian Sobchack, Jennifer Barker e Steven Shaviro 
em seu Cinematic Body. Tais autores buscam analisar como o corpo do expectador é convocado a participar durante a experiência de assistir um filme e como o corpo e o filme podem ser indissociáveis nesse processo (VIEIRA Jr., 2013).

Nesse artigo foram pensados filmes que apostam na proximidade ou ainda na intimidade do corpo e seus sentidos; principalmente o olfato e o paladar. Esse mergulho na fisicalidade da experiência ao assistir um filme é, muitas vezes, imperceptível ao espectador que se deixa levar por seus sentidos e suas memórias, que sente o filme em vez de apenas vê-lo, experimentando-o com todo o seu corpo - ou no caso aqui, com seus sentidos envolvidos no ato de comer.

Vieira Junior (2013) mostra que Jennifer Barker, em "Carnal Thoughts: embodiment and moving image culture", desenvolveu o conceito de pensar o filme como um corpo, já que o mundo está inscrito nele. A autora conclui que, exatamente pelo fato de cinema ser um corpo, este vai usar modos de existência corpóreos como visão, audição, mobilidade ou a produção de sensações físicas diversas como veículo e substância de sua linguagem. O corpo do filme em contato com o corpo do espectador inscrito no filme e no mundo estará sujeito a diversos estados físicos e emocionais - ansiedade, animação, sono, fome, sede - impregnados nesse corpo e trazidos, muitas vezes, antes de se começar a sessão.

Essas considerações podem ajudar a pensar nas diferentes formas de visualidade que usam a comida como recurso que pode, se não duplicar, pelo menos intensificar ou complexificar essa perspectiva sensória/gustativa. A questão que se deseja levantar aqui é: quando a comida é protagonista consciente da trama, como os órgãos do sentido são ativados no expectador? Esse artigo não teve o objetivo de responder a essa questão, mas ela pode ser o fio condutor de futuros estudos para investigar como outros órgãos do sentido são ativados no espectador que assiste a um filme sobre comida. Tal abordagem vai ao encontro da desconstrução da prevalência da visão ocularcêntrica frente à imagem, o que Vieira Junior (2013) chama de opticocentrismo.

A natureza de um mundo hiper-real baudrillardiano, que aperfeiçoa a realidade e tenta dissimular com absoluta perfeição as experiências que se propôs a representar, explica a busca de satisfação encontrada através do simulacro imagético/ sensorial/gustativo projetado nas imagens de comida. A visualidade alimentar se torna mais comida que a própria comida; um "engano autêntico" como diria Umberto Eco (1984, p.12), 
que permite o expectador se deixar enganar e saborear uma experiência para além da visual.

\section{NOTAS}

1. Informações disponíveis em: <http://portalsaude.saude.gov.br/images/ $\mathrm{pdf} / 2014 /$ novembro/o5/Guia-Alimentar-para-a-pop-brasiliera-Miolo-PDF-

-Internet.pdf>. Acesso em: 4 jan. 2015

2. Disponível em:< https://www.youtube.com/watch?v=VBdjkijD $7 \mathrm{PA}>$.

Acesso em: 6 maio 2015 .

3. Ver "Food and films Festivals" em:< http://www.nycfoodfilmfestival.com/>. Acesso em: 5 fev. 2015

4. Ver:< http://grandmasproject.org/>. Acesso em: 2 fev. 2016

\section{Referências}

AZEVEDO, E. Reflexões sobre riscos e o papel da ciência na construção do conceito de alimentação saudável. Revista de Nutrição, v.21, p.717-723, 2009.

Alimentação e modos de vida saudável. Saúde em Revista (UNIMEP). v.13, p.31- 36, 2004.

BARTHES, R. Toward a psychosociology of contemporary food consumption. In: COUNIHAN, C.; VAN ESTERIK, P (Ed.). Food and Culture. New York: New York Ed, 2008. p. 28-35.

CARDOSO, S.R.; ANTONIO, H.A.C. Comida, Sabor e Ação! A alimentação no Cinema como linguagem e identidade cultural. Baleia. Revista online do Grupo de Pesquisa e Estudos em Cinema e Literatura, 2006. Disponível em:< http:// revistas.marilia.unesp.br/index.php/baleianarede/article/ view/1377/1202>. Acesso em: 15 maio 2015.

CASAQUI, V.; CHIACHIRI, A.R. Estética e Sedução do Marketing: uma análise do Filme "A Fantástica Fábrica de Chocolate", 2007. Disponível em:< www.academia.edu/1498247/Estética_e_Sedução_do_Marketing_Uma_Análise_do_Filme_A_Fantástica_Fábrica_de_Chocolate>. Acesso em: 5 maio 2015.

COUTO, M. O Fio das Missangas. São Paulo: Cia das Letras, 2009.

DORIA, C. A. Entrevista com Santo Santamaria. O filósofo da Gastronomia, 2013. Disponível em: <http://wwwı.folha.uol. com.br/fsp/mais/fso602200506.htm>. Acesso em: 6 fev. 2013.

DURKHEIM, E. As formas elementares da vida religiosa. O sistema totêmico na Austrália. São Paulo: Martins Fontes, 1996. ECO, U. Viagem pela hiper-realidade. In: ECO, U. Viagem na irrealidade cotidiana. Rio de Janeiro: Nova Fronteira, 1984. p. 9-50. 
FERRAZ, M. O cozinheiro, o ladrão, sua esposa e o amante. 2012. Disponível em: <http://bocadoinferno.com.br/ criticas/2012/o1/o-cozinheiro-o-ladrao-sua-esposa-e-o-amante-1989/>. Acesso em: 6 fev. 2016.

FISCHLER, C. L'homnivore. Paris: Poche Odile Jacob, 2001.

GOLDENBERG, M. Cultura e gastro-anomia: psicopatologia da alimentação cotidiana. Entrevista com Claude Fischler. Horiz. antropol., v. 17, n. 36, 2011.

HELDKE, L. Let's cook: recipes for colonialism. In: INNESS, S.A. Pilaf, pozole, and pad thai: American women and ethnic food. Amherst: University of Massachusetts Press, 2001. p. 175-198.

JACOB, H. Gastronomídia: os ambientes midiáticos e as linguagens da comida e da cozinha. Revista Communicare, v. 12, n. 2, p. 113-125, 2012.

LIMA, C. Tachos e Panelas: Historiografia da alimentação brasileira. Recife: Mart Shopping, 1999.

MORIN, E. O paradigma perdido. Lisboa: Europa-América, 2000.

NASCIMENTO, A.B. Comida: prazeres, gozos e transgressões. Salvador: EDUFBA, 2007.

PINTO, R.K. Estômago, s/d. Disponível em:<http://www.telacritica.org/artigokokoltelacriticarevista7.htm>. Acesso em: 18 maio 2015.

PROENCA, R. P. C. Alimentação e globalização: algumas reflexões. Cienc. Cult., v. 62, n. 4, pp. 43-47, 2010.

RIBEIRO, C. M.; SOUZA, I.M.S. Gabriela, cravo e canela: mergulhando em seus temperos para problematizar gênero, sexualidade e relações de poder, 2006. Disponível em:< http://www.fastore.pt/museu/site/docs/Texto6.pdf >. Acesso em: 7 maio 2015.

SANTOS, A. D. Reconciliação e comunhão. 2010. Disponível em:< http://filosofiaeculturapop.blogspot.com. br/2010_06_o1_archive.html>. Acesso em: 23 maio 2016.

SANTOS, L. A. O corpo, o comer e a Comida: um estudo sobre as práticas corporais alimentares cotidianas a partir da cidade de Salvador. Salvador: EDUFBA, 2008.

SIANI , P. Cinema serve comida temática durante a exibição do filme em SP, 2014. Disponível em: <http://gi.globo.com/jornal-da-globo/noticia/2014/10/cinema-serve-comida-tematica-durante-exibicao-do-filme-em-sp.html>. Acesso em: 6 maio 2015.

TOLEDO, G. Comendo no Escuro, 2013. Disponível em:< http:// www1.folha.uol.com.br/paywall/signup.shtml?http:// www1.folha.uol.com.br/fsp/comida/129526-comendo-no-escuro.shtml>. Acesso em: 18 maio 2015. 
TUROW, E. Taste of Generation Yum: how the Millennial Generation's love for organic fare, celebrity chefs, and microbrews will make or break the future of food. Kindle E-book, 2015.

VIEIRA Jr., E.M. Corpo e sensorialidade nos meios audiovisuais contemporâneos. Apresentado no XIX Congresso da Sociedade Brasileira de Estudos do Cinema e Audiovisual, Campinas [ca 2013]. (Mimeografado).

Recebido em: 02/03/16

Aceito em: 16/05/16

\author{
ELAINE DE AZEVEDO \\ elainepeled@gmail.com \\ É Professora Adjunta no Depto de Ciências Sociais do Centro de Ciên- \\ cias Humanas e Naturais da Universidade Federal do Espírito Santo \\ (UFES). Coordena o Grupo de Pesquisa CNPq/UFES: Diálogos entre \\ Sociologia e Arte/ DISSOA.

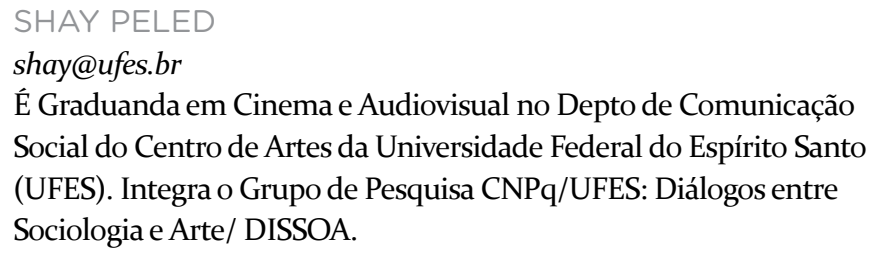

